\title{
Impact of lunar phase on the incidence of cardiac events
}

\author{
Rajan Kanth $^{1}$, Richard L. Berg ${ }^{2}$, Shereif H. Rezkalla ${ }^{3^{*}}$ \\ ${ }^{1}$ Department of Internal Medicine, Marshfield Clinic, Marshfield, USA \\ ${ }^{2}$ Biomedical Informatics Research Center, Marshfield Clinic Research Foundation, Marshfield, USA \\ ${ }^{3}$ Department of Cardiology, Marshfield Clinic, Marshfield, USA \\ Email: "rezkalla.shereif@marshfieldclinic.org
}

Received 27 April 2012; revised 29 May 2012; accepted 14 June 2012

\begin{abstract}
Objectives: Popular opinion holds that the phase of the moon influences human behavior, and several reports substantiate this claim; however, reports of correlation between the lunar cycle and cardiac events remain controversial. The purpose of the present study was to determine whether a relationship exists between lunar cycle and the occurrence of acute cardiac events. Methods: A retrospective review of cardiac events, including ST-elevated myocardial infarction (STEMI), non-ST elevated myocardial infarction (NSTEMI), and unstable angina, over a 5year period was performed. The dates of cardiac events were recorded and merged with the four phases of the lunar cycle (new moon, first quarter, full moon, and last quarter). Results: A total of 4751 cardiac events (578 STEMI, 1446 NSTEMI, 2727 unstable angina) occurred during the 5-year study period in 3935 unique patients. Cardiac events occurred equivalently during various phases of the lunar cycle. Conclusions: Despite popular opinion, our evidence suggests that the lunar cycle has no effect on the occurrence of acute coronary syndromes.
\end{abstract}

Keywords: Emergency Service/Hospital; Moon; Lunar Cycle; Myocardial Infarction; Acute Coronary Syndromes

\section{INTRODUCTION}

The perception that the moon can affect human behavior and other medical conditions is common amongst medical professionals [1,2]. There have been several reports of an influence of the lunar cycle on psychiatric disorders [3-6], aggressive behavior and crime [7-9], seizures $[10,11]$, suicide [12,13], absenteeism [14], conception [15], birth [16-19], menstruation [20,21], hospital admissions [22-24], and traffic accidents [25]. However, these studies are plagued by irreproducibility, and many more

\footnotetext{
*Corresponding author.
}

studies have found no association with the lunar cycle $[2,26]$. The association between the lunar cycle and the occurrence of acute coronary syndromes is no exception.

Several conflicting studies about the relationship between the lunar cycle and the occurrence of acute coronary syndromes have been published in peer-reviewed journals. In 1989, Sha et al. [27] evaluated the traditional Chinese medical theory that acute myocardial infarction (AMI) is associated with the lunar calendar. They found that AMI onset is maximal on the first day of the lunar calendar, during the new moon, and that an obvious trough in occurrence appears on the $15^{\text {th }}$ of the lunar month, which coincides with the full moon. Thereafter, occurrence gradually increases again until the beginning of the next lunar month. Similarly, Ooman et al. [28] evaluated the occurrence of acute coronary syndromes including unstable angina, ST-elevated myocardial infarction (STEMI), and non-ST elevated myocardial infarction (NSTEMI) from 1999 to 2001, a time span that included 30 new and full moons. Oooman and colleagues observed a significant difference in the number of admissions for acute coronary syndromes during different phases of the moon, with 223 admissions on days when the moon was full and 266 admissions when the moon was new $(P=0.005)$. In a conflicting report, Alves et al. [29] assessed the number of cardiopulmonary resuscitations performed in an emergency department over an 11-year period. Of 2,370,233 emergency room visits over 4018 days, 6837 cardiopulmonary resuscitations occurred. While there was no significant difference in the occurrence of cardiopulmonary resuscitations during the full moon $(P=0.97)$, there were $6.5 \%$ fewer cardiopulmonary resuscitations during new moon days $(P=0.02)$. Additionally, in a report of 127 attacks of atrial fibrillation over a 15-year period in a single patient, a peak in the number of attacks was observed under the full moon [30]. Finally, in a prospective study conducted from 1992 to 1998, Eisenberger et al. [31] found that acute myocardial infarction $(n=872)$ and cardiac arrest $(n=368)$ occurred on an equal percentage of days within each phase of the lunar cycle. These conflicting findings in the lit- 
erature make it difficult to draw any conclusions about the possible association between the lunar cycle and acute coronary syndromes.

There is some scientific basis for the potential effect of the lunar cycle on cardiovascular events. The occurrence of acute myocardial infarction varies on both a daily and a yearly basis, with more events occurring in the morning hours [32,33] and during the winter months [34]. Circadian variation in acute myocardial infarction appears to be related to the increased incidence of plaque rupture during the morning hours [35]. Additionally, there has been a report of a blind man whose circadian rhythm was based on the motion of the moon rather than the sun. Despite living in normal society, the blind man suffered from a cyclical sleep-wake disorder, and his patterns of body temperature, alertness, performance, cortisol secretion, and urinary electrolyte secretions were not synchronous with the normal 24-hour societal schedule, but rather appeared to coincide with the period of the lunar day [36]. Taken together, these studies suggest that both the sun and the moon may have some influence over biological functions. The objective of the current study was to test the hypothesis that more cardiac events occur during the full moon phase of the lunar cycle for consideration in the practice of emergency medicine and the staffing of emergency rooms.

\section{METHODS}

After receiving a waiver of informed consent from the Institutional Review Board, a retrospective study of all incidents of cardiovascular events in adults admitted to a tertiary care hospital in the 5-year period from 2006 to 2010 was conducted. Cardiovascular events included ST elevation myocardial infarction (STEMI), non-ST elevation myocardial infarction (NSTEMI), and unstable angina. Events were identified by International Statistical Classification of Diseases, Ninth Revision (ICD-9) code, and the date of event was abstracted from the patient's medical record. Prior to analysis, events were merged by date with data for the dates of the four phases of the moon (first quarter, full, last quarter, new). Information about the lunar cycle was obtained from the NASA website http://eclipse.gsfc.nasa.gov/phase/phase2001cst.html. The study period included 61 new moons and 62 full moons.

The primary study outcomes consisted of the numbers of patients per day having events. Events were identified through diagnostic codes in a comprehensive electronic medical record. Since the numbers of recorded encounters are substantially less on weekends and holidays, for analysis purposes, only business days (Monday through Friday) were included. To allow for variations in the timing of specific lunar phases with respect to calendar days, and to allow some separation between days included in adjacent phases, the primary analyses included the peak day of the lunar phase plus the two days prior and the two days following. So, for any one phase in any one lunar cycle, up to 5 days would be included in the analysis, depending upon which were business days.

In the primary study analyses, the number of events per day was analyzed by lunar phase using a very general class of statistical models, called generalized linear models and, more specifically, Poisson regression [37,38]. Analyses were conducted using SAS $^{\circledR}$ version 9.2 statistical software.

\section{RESULTS}

A total of 4751 cardiac events occurred in 3935 unique patients during the 5-year study period, including 578 cases of STEMI, 1446 cases of NSTEMI, and 2727 cases of unstable angina. The number of cardiac events that occurred per day during each phase of the lunar cycle is shown in Table 1. There was no statistically significant difference in the occurrence of any of the three cardiac events over the course of the lunar cycle (Table 1). Similarly, Figure 1 displays all observed events as a function of when they occurred during the lunar cycle and shows no obvious trends.

\section{DISCUSSION}

Consistent with a report by Eisenburger et al. [31], we detected no difference in the occurrence of acute cardiac events in any phase of the lunar cycle. In the present study, STEMI, NSTEMI, and unstable angina occurred at a similar frequency regardless of the phase of the moon.

Many believe that the gravitational pull of the moon accounts for the perceived effects of the lunar cycle on

Table 1. Analysis of cardiovascular events per day by lunar quarter estimates and 95\% confidence interval from Poisson models.

\begin{tabular}{|c|c|c|c|c|}
\hline Moon Phase & $\mathbf{n}^{*}$ & STEMI $(P=0.980)$ & NSTEMI $(P=0.614)$ & Unstable Angina $(P=0.239)$ \\
\hline First & 218 & $0.36(0.26-0.50)$ & $0.93(0.76-1.13)$ & $1.67(1.45-1.93)$ \\
\hline Full & 217 & $0.38(0.28-0.52)$ & $0.81(0.66-0.99)$ & $1.69(1.46-1.95)$ \\
\hline Last & 216 & $0.36(0.26-0.49)$ & $0.86(0.71-1.06)$ & $1.66(1.43-1.91)$ \\
\hline New & 212 & $0.36(0.26-0.50)$ & $0.88(0.72-1.08)$ & $1.88(1.64-2.17)$ \\
\hline
\end{tabular}

${ }^{*} \mathrm{n}$ = number of business days within $+/-2$ days. 


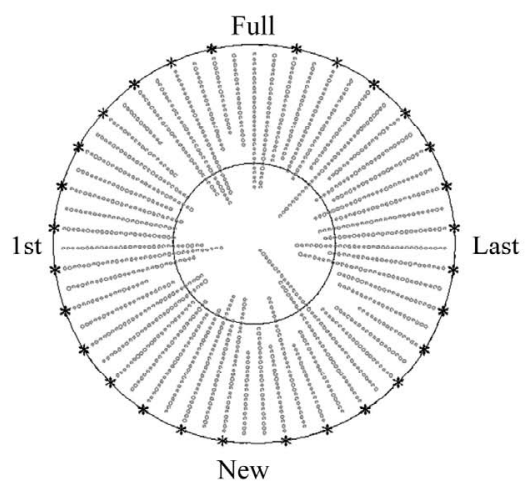

(a)

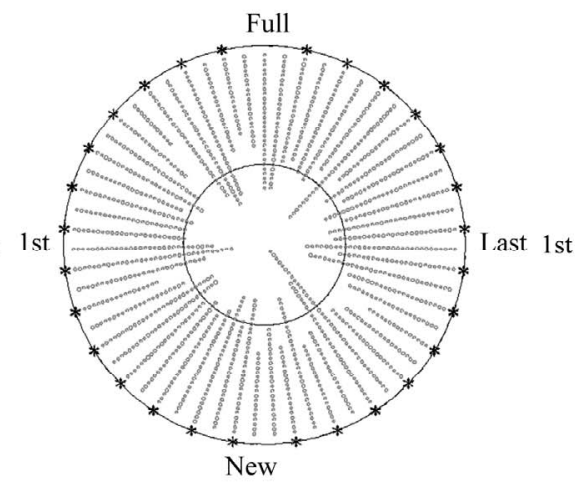

(b)

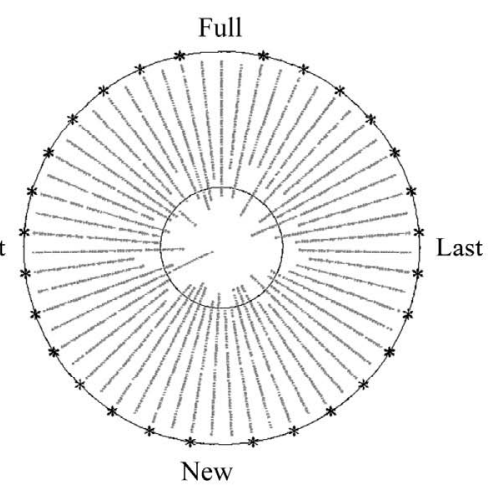

(c)

Figure 1. Phase of the moon for cardiovascular events. Graphic depiction of the number of the number of (a) STEMI, (b) non-STEMI, and (c) unstable angina events that occurred by phase of the moon. Each dot represents a single event, and events accumulate toward the center in 12-hour periods from the time of the full moon throughout the approximately 29-day lunar cycle. The median number of events per 12-hour period is shown by the inner circles.

human behavior and medical events. However, it is important to note that the gravitational pull of the moon, the force that influences the tides, is dependent not on the phase of the moon, but rather on the distance between the earth and the moon and the alignment of the moon, earth, and sun [2]. In 2008, Wake et al. [39] prospectively examined the association between the gravitation of the moon and the occurrence of acute myocardial infarction. A pattern was observed whereby there was a significant increase in the number of patients that experienced acute myocardial infarction when the gravitation of the moon was at its lowest (i.e., when the moon was furthest from the earth) over a 13-year period [39], suggesting that the moon may in fact have an effect on the occurrence of acute cardiac events, although not in the popular sense.

\subsection{Limitations}

There were a number of limitations to this study. Due to the retrospective nature of the study, the date of admission to the tertiary care hospital was considered the date of the cardiac event, although this may not have been the date for the actual onset of symptoms. We attempted to correct for this possibility by including the actual day of each phase of the moon plus or minus 2 days so that 5 days in each phase were assessed; however, it is still possible that the date of actual onset was missed. Additionally, only patients admitted to the hospital were included in the study, which does not include individuals who expired as a result of a cardiac event outside of the hospital. Finally, the patient population of north central Wisconsin does not necessarily represent patient populations elsewhere, limiting the generalizability of the results to other areas, particularly more urban areas.

\subsection{Conclusion}

With respect to acute cardiac events, the idea that fre- quency is affected by the phases of the lunar cycle could not be substantiated. Therefore, based on our results, lunar cycle should not be a consideration in staffing of the emergency room or the practice of emergency medicine for the purpose of caring for patients in cardiac distress.

\section{ACKNOWLEDGEMENTS}

The authors thank the Marshfield Clinic Research Foundation's Office of Scientific Writing and Publication for assistance in the preparation of this manuscript.

\section{REFERENCES}

[1] Vance, D.E. (1995) Belief in lunar effects on human behavior. Psychological Reports, 76, 32-34. doi:10.2466/pr0.1995.76.1.32

[2] Foster, R.G. and Roenneberg, T. (2008) Human responses to the geophysical daily, annual and lunar cycles. Current Biology, 18, R784-R794. doi:10.1016/j.cub.2008.07.003

[3] Templer, D.I. and Veleber, D.M. (1980) The moon and madness: A comprehensive perspective. Journal of Clinical Psychopharmacology, 36, 865-868.

[4] Temte, J.L. (1989) Exploring environmental cycles in psychiatric patients. Wisconsin Medical Journal, 88, 1720.

[5] Parmeshwaran, R., Patel, V. and Fernandes, J.M. (1999) Lunar phase and psychiatric illness in Goa. Indian Journal of Psychiatry, 41, 60-65.

[6] Barr, W. (2000) Lunacy revisited. The influence of the moon on mental health and quality of life. Journal of Psychosocial Nursing and Mental Health Services, 38, 835.

[7] Lieber, A.L. (1978) Human aggression and the lunar synodic cycle. Journal of Clinical Psychiatry, 39, 385-392.

[8] Thakur, C.P. and Sharma, D. (1984) Full moon and crime. British Medical Journal (Clinical Research Ed.), 289, 1789-1791. doi:10.1136/bmj.289.6460.1789 
[9] Calver, L.A., Stokes, B.J. and Isbister, G.K. (2009) The dark side of the moon. Medical Journal of Australia, 191, 692-694.

[10] Benbadis, S.R., Chang, S., Hunter, J. and Wang, W. (2004) The influence of the full moon on seizure frequency: Myth or reality? Epilepsy \& Behavior, 5, 596-597. doi:10.1016/j.yebeh.2004.04.001

[11] Polychronopoulos, P., Argyriou, A.A., Sirrou, V., et al. (2006) Lunar phases and seizure occurrence: Just an ancient legend? Neurology, 66, 1442-1443. doi:10.1212/01.wnl.0000210482.75864.e8

[12] Jones, P.K. and Jones, S.L. (1977) Lunar association with suicide. Suicide and Life-Threatening Behavior, 7, 31-39.

[13] Martin, S.J., Kelly, I.W. and Saklofske, D.H. (1992) Suicide and lunar cycles: A critical review over 28 years. Psychological Reports, 71, 787-795. doi:10.2466/pr0.1992.71.3.787

[14] Sands, J.M. and Miller, L.E. (1991) Effects of moon phase and other temporal variables on absenteeism. Psychological Reports, 69, 59-962.

[15] Weigert, M., Kaali, S.G., Kulin, S. and Feichtinger, W. (2002) Do lunar cycles influence in vitro fertilization results? Journal of Assisted Reproduction and Genetics, 19, 539-540. doi:10.1023/A:1020968020504

[16] Criss, T.B. and Marcum, J.P. (1981) A lunar effect on fertility. Society of Biology, 28, 75-80.

[17] Guillon, P., Guillon, D., Lansac, J., et al. (1986) Births, fertility, rhythms and lunar cycle. A statistical study of 5,927,978 births. Journal de Gynécologie, Obstétrique et Biologie de la Reproduction, 15, 256-271.

[18] Ghiandoni, G., Seclì, R., Rocchi, M.B. and Ugolini, G. (1998) Does lunar position influence the time of delivery? A statistical analysis. European Journal of Obstetrics \& Gynecology and Reproductive Biology, 77, 47-50. doi:10.1016/S0301-2115(97)00226-1

[19] Ghiandoni, G., Seclì, R., Rocchi, M.B., et al. (1998) Some unexpected results in time distribution analysis of spontaneous deliveries. Gynecologic and Obstetric Investigation, 46, 88-90. doi:10.1159/000010008

[20] Cutler, W.B. (1980) Lunar and menstrual phase locking. American Journal of Obstetrics \& Gynecology, 137, 834-839.

[21] Law, S.P. (1986) The regulation of menstrual cycle and its relationship to the moon. Acta Obstetricia et Gynecologica Scandinavica, 65, 45-48. doi:10.3109/00016348609158228

[22] Payne, S.R., Deardon, D.J., Abercrombie, G.F. and Carlson, G.L. (1989) Urinary retention and the lunisolar cycle: Is it a lunatic phenomenon? British Medical Journal, 299, 1560-1562. doi:10.1136/bmj.299.6715.1560

[23] Mikulecký, M. and Schréter, I. (1993) Occurrence of acute infectious diarrhea during the lunar phases. Casopis Lekaru Ceskych, 132, 498-501 (in Czech).

[24] Román, E.M., Soriano, G., Fuentes, M., et al. (2004) The influence of the full moon on the number of admissions related to gastrointestinal bleeding. International Journal of Nursing Practice, 10, 292-296. doi:10.1111/j.1440-172x.2004.00492.x

[25] Alonso, Y. (1993) Geographical variables and behavior: LXXII. Barometric pressure, lunar cycle, and traffic accidents. Perceptual \& Motor Skills, 77, 371-376. doi:10.2466/pms.1993.77.2.371

[26] Zimecki, M. (2006) The lunar cycle: Effects on human and animal behavior and physiology. Postęy Higieny $i$ Medycyny Doświadczalnej, 60, 1-7.

[27] Sha, L.R., Xu, N.T., Song, X.H., et al. (1989) Lunar phases, myocardial infarction and hemorrheological character. A Western medical study combined with appraisal of the related traditional Chinese medical theory. Chinese Medical Journal (English Edition), 102, 722-725.

[28] Oomman, A., Ramachandran, P., Shanmugapriya, et al. (2003) A novel trigger for acute coronary syndromes: The effect of lunar cycles on the incidence and in-hospital prognosis of acute coronary syndromes-A 3-year retrospective study. Journal of the Indian Medical Association, 101, 227-228.

[29] Alves, D.W., Allegra, J.R., Cochrane, D.G. and Cable, G. (2003) Effect of lunar cycle on temporal variation in cardiopulmonary arrest in seven emergency departments during 11 years. European Journal of Emergency Medicine, 10, 225-228. doi:10.1097/00063110-200309000-00013

[30] Mikulecky, M. and Valachova, A. (1996) Lunar influence on atrial fibrillation? Brazilian Journal of Medical and Biological Research, 29, 1073-1075.

[31] Eisenburger, P., Schreiber, W., Vergeiner, G., et al. (2003) Lunar phases are not related to the occurrence of acute myocardial infarction and sudden cardiac death. Resuscitation, 56, 187-189. doi:10.1016/S0300-9572(02)00298-8

[32] Hjalmarson, A., Gilpin, E.A., Nicod, P., et al. (19890 Differing circadian patterns of symptom onset in subgroups of patients with acute myocardial infarction. Circulation, 80, 267-275. doi:10.1161/01.CIR.80.2.267

[33] Willich, S.N., Linderer, T., Wegscheider, K., et al. (1989) Increased morning incidence of myocardial infarction in the ISAM Study: Absence with prior beta-adrenergic blockade. ISAM Study Group. Circulation, 80, 853-858. doi:10.1161/01.CIR.80.4.853

[34] Kloner, R.A., Poole, W.K. and Perritt, R.L. (1999) When throughout the year is coronary death more likely to occur? A 12-year population-based analysis of more than 220,000 cases. Circulation, 100, 1630-1634. doi:10.1161/01.CIR.100.15.1630

[35] Tanaka, A., Kawarabayashi, T., Fukuda, D., et al. (2004) Circadian variation of plaque rupture in acute myocardial infarction. American Journal of Cardiology, 93, 1-5. doi:10.1016/j.amjcard.2003.09.002

[36] Miles, L.E., Raynal, D.M. and Wilson, M.A. (1977) Blind man living in normal society has circadian rhythms of 24.9 hours. Science, 198, 421-423. doi:10.1126/science.910139

[37] Lawless, J.F. (1987) Regression methods for Poisson process data. Journal of the American Statistical Association, 82, 808-815.

[38] McCullagh, P. and Nelder, J.A. (1989) Generalized linear 
models. 2nd Edition, Chapman and Hall, London.

[39] Wake, R., Yoshikawa, J., Haze, K., et al. (2008) The gravitation of the moon plays pivotal roles in the occur- rence of the acute myocardial infarction. Environ Health Insights, 31, 63-66. 